\title{
To blend or not to blend? Consumer attitudes towards mandatory use of ethanol-blended fuel in Zimbabwe
}

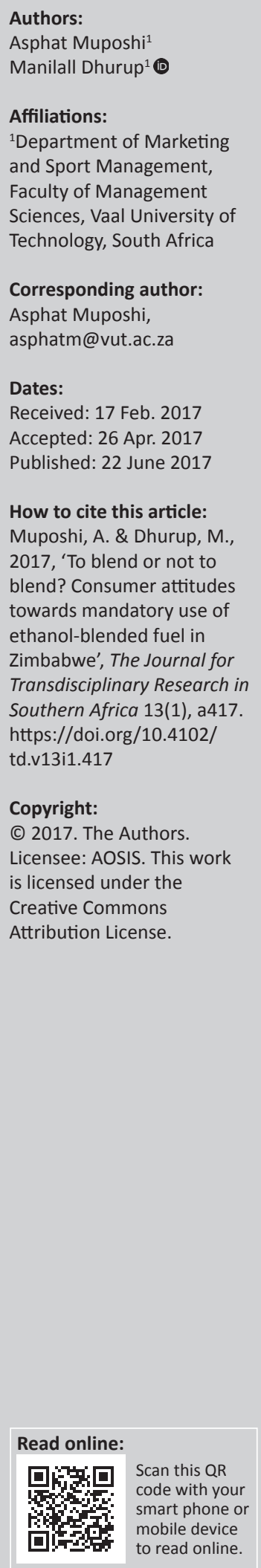

Worldwide, the use of bioethanol is proliferating as an alternative to fossil fuels. Consistent with this trend, the Zimbabwean government mandated the blending of unleaded petrol with $10 \%$ ethanol. As the use of ethanol-blended fuel is still at the infancy stage in Zimbabwe, the objective of this study was to explore consumer attitudes towards mandatory use of ethanolblended petrol. The study employed a qualitative research design, and data were collected using semi-structured in-depth interviews from motorists who regularly use blended fuel. Thematic content analysis was used to analyse interview transcripts. The study showed that the market acceptance of blended fuel remains low in Zimbabwe. The main themes that characterised consumer attitudes towards blended fuel were cynicism, misinformation, unavailability and risk perception. Overall, the study found that the use of ethanol-blended fuel remains a contested terrain in Zimbabwe and there is a need for consumer education to correct misconceptions prevailing in the marketplace.

\section{Introduction and background to the study}

In recent years, motorists have witnessed the resurgence of biofuel as an alternative to fossil fuels (Algier 2014; Jaeger \& Egelkraut 2011; Kallas \& Gil 2014). Biofuel lost its market appeal during the 21st century owing to the growth of the petroleum industry (Cacciatore, Scheufele \& Shaw 2012). The renewed interest in biofuel is spurred by the need to reduce greenhouse gases, growth in climate change concerns and volatility of global oil prices (Khachatryan, Joireman \& Casavant 2013; Pacini et al. 2013). For this reason, several countries have crafted and implemented policies and legislation aimed at promoting the use of biofuel (Negash \& Swinnen 2013; Proost \& Van Dender 2012). Globally, Brazil, the United States and China are the top producers of biofuel (Hertel \& Tyner 2013).

In southern Africa, Mozambique, Zambia, South Africa, Malawi and Zimbabwe are some of the countries that have invested significantly in the production of biofuel (Saruchera, Phiri \& Chitakunye 2014). This was motivated by the significant potential of biofuel in southern African countries owing to favourable climatic conditions for the production of biofuel crops (Chakauya, Beyene \& Chikwamba 2009). In southern Africa, the use of bioethanol has largely been promoted by way of mandates ranging from E2 to E10 in South Africa and E10 in Mozambique, Zambia, Zimbabwe and Malawi (Henley 2014). According to Henley, Malawi is the only southern African country that has managed to successfully implement and sustain biofuel mandates since 1982.

\section{Contextual setting of the study}

The study took place in Zimbabwe, where the mandatory use of ethanol-blended fuel continues to generate polarised views from key stakeholders (Chawafambira 2014; Pickelsimer \& Esterhuizen 2011; Thondhlana 2014). In Zimbabwe, the use of ethanol as a fuel blend started in the early 1980s but was later suspended because of the 1992 drought that affected the production of sugar cane (Saccharum officinarum) (Chakauya et al. 2009). Interest in biofuel was reignited by acute fuel shortages in the early to mid-2000s coupled with the need to reduce over-reliance on imported fuel (Saruchera et al. 2014). The Zimbabwean government's biofuel policy promotes the use of Jatropha (Jatropha curcas) and sugar cane for the production of biofuel (Pickelsimer \& Esterhuizen 2011). To demonstrate its commitment to migrate to biofuel, in 2007, the Zimbabwean government commissioned a biodiesel plant with a capacity to produce 10000 litres per annum in Mount Hampden (Saruchera et al. 2014). This was followed by the installation of an ethanol distillery plant with an estimated annual capacity of 100 million litres of ethanol in Chisumbanje in southeastern Zimbabwe in 2011 (Pickelsimer \& Esterhuizen 2011). The Chisumbanje ethanol project is supported by Triangle Limited and Hippo Valley Limited, which are the main sugar milling companies in Zimbabwe (Pickelsimer \& Esterhuizen 2011). 
In October 2013, through Statutory Instrument 17, the Zimbabwean government directed the mandatory blending of unleaded petrol with 5\% locally produced ethanol (Ministry of Energy and Power Development 2013). In November 2013, the blending ratio was increased to E10, which is a volumetric mixture of $10 \%$ ethanol and $90 \%$ petrol (Pembere 2013). Currently, Green Fuel Ltd is the only company that has the licence to produce ethanol for blending purposes in Zimbabwe (Saruchera et al. 2014). It is envisaged that in the long-term, bioethanol will contribute a significant percentage of Zimbabwe's liquid fuel consumption (Pickelsimer \& Esterhuizen 2011).

\section{Problem statement}

The mandatory blending of petrol with ethanol (E10) was received with mixed views in Zimbabwe (Pembere 2013; Pickelsimer \& Esterhuizen 2011). Critics of ethanol-blended fuel pointed out its threats to environmental sustainability and food security (Lazarus 2014; Thondhlana 2014). Supply chain bottlenecks were also reported as a number of fuel distributors were reluctant to stock and sell blended fuel (Moyo et al. 2014; Saruchera et al. 2014). Additionally, a trend was noted where motorists deliberately avoided using blended fuel and in some instances convinced with fuel distributors to sell them unblended fuel (Chawafambira 2014). However, proponents of biofuel heralded it as a solution to energy security (Chakauya et al. 2009). Given this background, this study explored consumer attitudes towards mandatory use of blended fuel in Zimbabwe.

It is worth noting that previous studies that have been conducted thus far focused mainly on the social impact of ethanol production and its effect on sustainable development (Moyo et al. 2014; Thondhlana 2014). Until now, little was known about consumer attitudes towards the use of blended fuel in Zimbabwe. This is despite the fact that consumer attitudes play a pivotal role in the market acceptance of biofuel (Aguilar et al. 2015). This study, therefore, sought to answer the following research question: What are consumer attitudes towards mandatory use of ethanol-blended fuel in Zimbabwe?

\section{Significance of the study}

The use of ethanol-blended fuel is situated within the global debates on food security, climate change, environmental conservation and sustainable development (Petrolia et al. 2010). The fact that the use of ethanol-blended fuel is mandated by the Zimbabwe government and criticised by key stakeholders such as motorists, car manufacturers and fuel distributors raises pertinent questions such as: Do motorists in Zimbabwe perceive the production of ethanol as beneficial to the natural environment? Do Zimbabweans perceive the production of ethanol as a threat to food security? Do motorists in Zimbabwe consider the use of ethanol-blended fuel as a way of reducing over-dependence on imported fuel? Do motorists in Zimbabwe perceive the use of ethanol-blended fuel as a stimulus to economic growth? This study attempts to answer the foregoing questions with the objective of informing Zimbabwean government's policy on the use of blended fuel.

\section{Literature review}

\section{Bioethanol production, food-fuel nexus and environmental sustainability debate}

Bioethanol is emerging as an environment-friendly alternative to fossil fuel and its use is growing substantially (Khachatryan et al. 2013). Bioethanol is classified under the first-generation group of biofuels (Kallas \& Gil 2014), which refer to a cohort of biofuels produced from food crops such as sugar cane, corn and sugar beets (Lee \& Lavoie 2013). One of the advantages of using bioethanol as a fuel is that relatively less carbon dioxide is emitted as compared to fossil fuels (Van de Velde et al. 2009). This is particularly important in this era in which concerted efforts are being taken globally to reduce greenhouse gases (Kallas \& Gil 2014; Smith et al. 2013). Additionally, the production of bioethanol contributes to employment creation, economic growth, infrastructure development and energy security (Florin, Van de Ven \& Van Ittersum 2014; Smith et al. 2013).

Despite the noted advantages, the production of bioethanol is constrained by competing social, economic and environmental goals (Cacciatore et al. 2012; Mohr \& Raman 2013). Food security is one of the major counter-arguments against the production of bioethanol (Selfa et al. 2011). In what has been dubbed the 'food-fuel nexus', opponents of bioethanol argue that food security is threatened when significant portions of arable land are devoted to sugar cane production (Huang et al. 2012). For example, the increase in food prices in the United Kingdom between 2007 and 2008 was attributed to the growth in ethanol plantations that displaced food production (Mohr \& Raman 2013). In order to reduce the food-fuel conflict, Murphy et al. (2011) stress the need to formulate land management policies that promote synergies between food and fuel production. In the same vein, Sims et al. (2010) suggest the use of marginal land or degraded land rather than arable land in ethanol production.

Other drawbacks of ethanol production include loss of entitlement to land by communities, social exclusion of local communities in ethanol projects and environmental degradation (Florin et al. 2014). For instance, in 2011, infringements of human rights were reported in Zimbabwe's Chisumbanje area where people were displaced to pave way for the ethanol plant. According to Pickelsimer and Esterhuizen (2011), this resulted in people being deprived of their land resulting in loss of livelihoods. Critics of biofuel also contend that the intensive use of fertilisers and water in ethanol production results in loss of biodiversity (Campbell \& Doswald 2009; Pilgrim \& Harvey 2010). In addition, the possibility of a 'blending wall' is one of the major challenges that negatively affect the long-term prospects of bioethanol (Zhang, Qui \& Wetzstein 2010). According to Aguilar et al. (2015), blending wall refers to a saturation point where limitations in blending ratios will ultimately result in excess 
supply, which potentially render further ethanol production unviable. Although increasing blending ratios may seem to be a possible solution to the blending wall, Aguilar et al. (2015) note that this route is belied by uncertainty over market acceptance and large-scale availability of flex-fuel cars. Because of the aforementioned challenges, Zhang et al. (2010) argue that it remains a challenge to ascertain with certainty the net environmental benefits of bioethanol. Notwithstanding the aforementioned challenges, Pilgrim and Harvey (2010) note that bioethanol may prove to be a good alternative to fossil fuel if it is supported by strong governance premised on monitoring the environmental and social impact.

\section{Research methodology}

The study was underpinned by the constructivism research paradigm. This research paradigm is generally recommended in exploratory studies (Creswell 2009). The use of ethanol-blended fuel is at infancy stage in Zimbabwe and, as such, constructivism research paradigm was considered as suitable for the study. Additionally, by employing this paradigm the researcher was able to understand the lived experiences of participants in their interface with the phenomenon under study (Guba \& Lincoln 1994). Consistent with the constructivism research paradigm, by utilising in-depth interviews, the researcher managed to coconstruct knowledge relating to consumer attitudes towards ethanol-blended fuel with the participants.

In-depth interviews were selected as a research approach because they gave the researcher the opportunity to probe and clarify the views raised by participants (Babbie 2013). In addition, semi-structured interviews accorded the researcher the flexibility to engage with participants with the aim of getting detailed insights of the phenomenon under study (Fouché \& De Vos 2011). The target population of this study was motorists who use blended fuel. The participants were selected through the use of the purposive sampling method. This method was preferred as it allowed the researcher to select participants who were more knowledgeable about biofuel. The use of purposive sampling was particularly important given the prevalence of misconceptions and myths that characterises the use of ethanol-blended fuel in Zimbabwe (Saruchera et al. 2014). Additionally, purposive sampling was employed as it enhanced the collection of rich data (Bryman \& Bell 2015).

\section{Data collection}

Data were collected from motorists who use ethanol-blended petrol in Harare, Zimbabwe. Harare was considered as the ideal setting for this study because of its stature as the economic hub of Zimbabwe and it has high volumes of fuel consumption as compared to other cities (Shonhiwa, Nhamo \& Chinguwa 2013). Semi-structured, in-depth interviews were conducted in Harare from 26 June to 8 July 2016 with the aid of an interview guide. The interview guide consisted of questions on motorists' knowledge of blended fuel, attitudes towards ethanol-blended petrol and factors that influence or inhibit the use of ethanol-blended petrol. Prior to interviews, a pilot study was conducted with three participants to assess the appropriateness of the questions as well as to gauge the general attitude of participants towards the study. Following the results of the pilot study, minor adjustments were effected to the interview guide.

Participants were screened by asking a general broad question on ethanol-blended fuel. Only participants who showed detailed knowledge and enthusiasm on the subject were considered for in-depth interviews. The venues for the interviews were selected based on the convenience and accessibility of participants. After securing their consent, interviews were conducted following same procedures. With prior permission of participants, all interviews were recorded digitally and supplementary notes were jotted down. The recorded transcripts and interview notes were labelled properly for each interview. The dates of the interview including the gender of participants were indicated clearly. Pseudo-names were used to enhance confidentiality and anonymity of participants. The duration of interviews ranged from 40 to 60 minutes. Guided by principle of theoretical saturation of Strauss and Corbin (1998), interviews were conducted up to the point when no new information was emerging from participants. Theoretical saturation was deemed to be achieved by the 20th interview.

\section{Data analysis}

Thematic content analysis was used to analyse data collected from in-depth interviews. This method involved identifying, analysing and reporting themes within the data $\left(\mathrm{O}^{\prime} \mathrm{Brien}\right.$ et al. 2014). Using verbatim interview transcripts, thematic content analysis followed a three-stage process suggested by Strauss and Corbin (1998). The first stage involved listening to the audio-recorded interview transcripts and glancing through the interview notes with the objective of getting the general sense of the data. An iterative process was used to coalesce and classify emergent themes into broad categories. The objective of this stage was to capture as far as possible all pertinent concepts from interview transcripts (Lawrence \& Tar 2013).

The second stage, known as axial coding (Strauss \& Corbin 1998), involved a detailed re-evaluation of interview notes with the objective of collapsing broad themes identified during open coding into specific themes. Axial coding was done by identifying the interrelationships between subthemes and merging them based on the associations between them (Lawrence \& Tar 2013). The final stage, called selective coding (Strauss \& Corbin 1998), involved the process of naming themes that emanated from the study including a concise qualitative description of each theme.

\section{Trustworthiness of the study}

The study employed a number of strategies to enhance reliability and validity of findings. Firstly, measures to enhance the trustworthiness of this study were incorporated 
deliberately in the research design process. Effort was made to ensure that the sample was suitable for the study by employing purposive sampling ( $\mathrm{O}^{\prime}$ Brien et al. 2014). Secondly, a pilot study was conducted to enhance the reliability of interview questions (Graneheim \& Lundman 2004). Thirdly, the anonymity and confidentiality of all participants were guaranteed through the use of pseudonames to ensure the generation of valid responses (Silverman \& Marvasti 2008). Fourthly, member checks were undertaken in which six participants who were readily available were requested to validate whether their views were properly captured in the study. The participants agreed that the themes that emerged from data analysis adequately captured views raised in the interviews. Lastly, the interview transcripts were also independently analysed by two experts who were not directly involved in the study and there was consensus on the themes that emerged from the study.

\section{Results and discussion}

This section presents the profile of participants and discusses the themes that emerged from data analysis. Representative excerpts from interview transcripts are used to support the discussion. The findings of the study are discussed as follows:

\section{Sample composition}

The sample consisted of $75 \%(n=15)$ men and $25 \%(n=5)$ women. The over-representation of male participants is a common feature in surveys involving Zimbabwean motorists because there are more male than female drivers. In terms of education, almost half of the participants $(55 \% ; n=11)$ had attained a diploma, 30\% $(n=6)$ were degree holders and 15\% had attained an advanced-level certificate. The majority age was $40-45$ years $(60 \%)$ followed by $35-39$ years $(30 \%)$ and $46-50$ years (10\%). All participants had more than five years of driving experience. In terms of ethnicity, the majority of the participants, $70 \%(n=14)$, were black ethnicity and 30\% $(n=6)$ were of mixed ethnicity. In terms of occupation, eight were teachers, four were mechanics, three were lecturers and five were self-employed entrepreneurs.

The themes that emerged from data analysis were blending gap, cynicism, perceived risk, unavailability and unethical product. The themes are discussed as follows:

\section{Blending gap}

The majority of participants $(75 \%)$ pointed to the existence of a 'blending gap'. The presence of the blending gap was manifested when participants acknowledged the potential benefits of using blended fuel yet at the same time expressed reluctance to use it. In particular, almost three-quarters of the participants rationalised their apathy towards blended fuel by citing its low energy content as compared to unblended fuel. Tom's comment, for instance, indicated the prevalence of the blending gap:

'Given our background of fuel shortages ... blended fuel is a noble idea ... but for me the decision to use blended or unblended petrol is informed by value for money.' (Tom, 41, Male, Teacher)
'If I was given a choice I would prefer unblended fuel because I can drive more kilometres than when I am using blended.' (Pinky, 36, Female, Lecturer)

The inferior tag attached to ethanol-blended fuel by Pinky was also reported in previous studies on bioethanol acceptance (Tyner \& Viteri 2010) and other products with pro-environmental attributes (Hartmann \& ApaolazaIbanez 2012). Earlier studies conducted by Gan et al. (2008) as well as Ginsberg and Bloom (2004) also note that consumers were not prepared to sacrifice quality for the sake of supporting environmental sustainability goals. Based on this result, implementation of strategies aimed at bridging the blending gap needs to be prioritised. To do this, Moyo et al. (2014) stresses the importance of generating awareness among the motoring public on the environmental, social and economic benefits of switching to blended fuel.

\section{Consumer cynicism}

The majority of study participants (80\%) expressed scepticism towards the mandatory use of ethanol-blended fuel. Because of this scepticism, respondents indicated their unwillingness to use blended fuel. The sense of cynicism was explained by Bobby in the following excerpt:

'I really support the idea of blended fuel but the way it was introduced everything is secretive ... you have one company benefiting, the biofuel policy and pricing model is not clear ... this blending thing was forced on people without our input.' (Bobby, 44, Male, Entrepreneur)

It is evident from the foregoing excerpt that the motorist perceives the use of blended fuel as a burden that was imposed on him. This feeling of being coerced resulted in negative attitudes towards blended fuel. This finding was also reported in previous similar studies (Ricci, Bellaby \& Flynn 2010; Rogers et al. 2012) where lack of public consultation was cited as a key driver of consumer cynicism towards the use of bioethanol. For instance, Rogers et al. (2012) note that lack of public involvement and participation in biofuel policy breeds a cohort of passive and unreflective consumers, and this acts as an impediment to mainstream adoption of biofuel. Consumer scepticism was heightened by perceptions of unfair pricing as shown by Tom's remark:

'When blending was introduced we thought that fuel price was going to be cheaper ... but look we are still paying more even when global fuel prices are going down ... we are being ripped off.' (Tom, 41, Male, Teacher)

This view underscores the importance of transparency in the pricing of blended fuel. In order to generate primary demand, Saruchera et al. (2014) recommended the use of incentives such as subsidies in order to promote market acceptance of blended fuel. This finding also points to the need for a comprehensive biofuel policy that considers the inputs of all key stakeholders. 


\section{Perceived risk}

The majority of participants $(70 \%)$ indicated that their unwillingness to use ethanol-blended fuel was influenced by risks posed. The main concerns of motorists were centred on the compatibility of blended fuel with vehicle engines. These sentiments are illustrated by the following comments:

'I am afraid to use blended fuel because I hear people saying it damages the engine ... I don't know whether blending ratios will be increased or not ... which car to buy ... even flex-fuel cars are still very limited here.' (Paddy, 36, Male, Mechanic)

'I use blended fuel but I noticed that my engine is no longer performing well ... I always visit a mechanic now ... he told me that this fuel is corrosive and advised me to buy a fuel upgrade kit.' (Prim, 35, Female, Entrepreneur)

The risk perceived by study participants adds on to the prevailing debate on the safety of blended fuel. This finding was also confirmed in a previous study by Saruchera et al. (2014), which identified misinformation as one the barriers to the adoption of biofuel. In an attempt to address risks perceived by motorists, the Ministry of Energy and Power Development (2013) advised that the blending ratio of E10 complies with international standards and is compatible with most car engines in Zimbabwe. Overall, this finding underscores an urgent need for consumer education to allay misconceptions associated with the use of ethanol-blended fuel in Zimbabwe.

An undercurrent of uncertainty also fuels the perception of risk over the Zimbabwean government's long-term policy on the use of ethanol-blended fuel as captured in the following excerpt:

'The whole issue is confusing ... at one point we were told that the blending ratio was increased to E15 and was later reduced to E10 ... some are saying it will be increased to E20 by year end ... if you want to buy a new car it's all confusing.' (Timmy, 48, Male, Mechanic)

It is evident from Timmy's comment that uncertainty regarding government policy on blending ratios is diluting consumer confidence. In order to reduce uncertainty, there is need for a long-term policy on biofuel that is communicated well to the motoring public.

\section{Unethical product}

The majority of participants $(75 \%)$ regard ethanol-blended fuel as an unethical product associated with a number of societal costs. In particular, the overriding concern among most participants was that consumer rights and social responsibility obligations were sacrificed in an attempt to enhance energy security. This view was captured in the following excerpts:

'I know a lot of my relatives who were deprived their land when that ethanol plant was built ... they were promised jobs and financial compensation but up to now nothing happened and the government is not doing anything that's why I shun anything associated with this fuel.' (Hazy, 39, Female, Teacher)
'As a consumer I value my right to choose ... by making the use of blended fuel mandatory, I believe my right to choose was violated.' (Harry, 48, Male, Lecturer)

The foregoing quotes suggest that study participants felt a sense of psychological disengagement from the use of blended fuel. For example, Hazy's comment suggests that the tone of disengagement emanates from lack of tangible societal and individual benefits accruing from the use of ethanol-blended fuel. In order to enhance public acceptance of bioethanol, Peters, Fudge and Sinclair (2010) stress the need for stakeholder involvement and effective monitoring of economic, social and environmental impact of biofuel production.

\section{Unavailability}

There was broad consensus from participants that the use of ethanol-blended fuel was inconvenient because of its limited availability. This view is captured in the following excerpts:

'If we are to use biofuel we need to get our supply in order ... in most cases fuel stations ran out of fuel and people waste a lot of time looking for fuel.' (Pinky, 36, Female, Lecturer)

Another widely held view (65\%) associated with unavailability of blended fuel was limited blending infrastructure. This view is encapsulated by the following comment:

'I don't make sense why the government grant licence to one company to supply the whole country ... the blending facilities is very few and this result in shortages.' (Hazy, 39, Female, Teacher)

Hazy's comment resonates with the findings of the study conducted by Zapta and Nieuwenhuis (2009), which found that instability in bioethanol supply results in perceptions of energy insecurity, which in turn affects adoption levels. Overall, this result underscores the need to enhance capacity and supply of bioethanol in Zimbabwe. For instance, Moyo et al. (2014) note that mandatory blending is only effective if a stable supply chain backs it. In order to enhance availability, Moyo et al. (2014) suggested the need to build capacity in terms of installation of blending pumps, storage tanks and distribution infrastructure compatible with E10.

\section{Limitations of the study}

The findings of this study need to be considered in view of three notable limitations. Firstly, the study employed a qualitative research design, which limits the generalisability of results. Future studies may employ a survey method in order to generalise the findings to a broader population. Secondly, this study relied on cross-sectional data, which limited the researcher in observing the changes in motorists' attitudes towards blended fuel in the long-term. Thirdly, the study was based on one developing country and this limits the extendibility of findings to other developing countries in Africa. Despite the noted limitations, the study offers a solid foundation for policymakers to develop policies that have 
the potential to enhance mainstream voluntary adoption of ethanol-blended fuel.

\section{Conclusion}

The aim of this study was to explore consumer attitudes towards mandatory ethanol blending in Zimbabwe. The results of the study showed that motorists have negative attitudes towards the use of blended fuel. Cynicism, perceived risk, misinformation and unavailability were identified as the main impediments that need to be addressed to enhance the adoption of ethanol-blended fuel in Zimbabwe. There is also a need for an integrated assessment of the environmental, social and economic implications of the use of blended fuel in Zimbabwe. This will enable the government to formulate long-term policies for the implementation and coordination of the use of blended fuel in Zimbabwe. The study also points to the need for capacity building to enhance availability, consumer education and stakeholder involvement in order to enhance the market acceptance of blended fuel. Overall, the study provides valuable insights to other southern African countries that intend to mandate the use of ethanol-blended fuel.

\section{Acknowledgements}

The authors thank the Faculty of Management Sciences at Vaal University of Technology for sponsoring the publication of this article.

\section{Competing interests}

The authors declare that they have no financial or personal relationships which may have inappropriately influenced them in writing this article.

\section{Authors' contributions}

A.M. was responsible for formulating the problem statement, conducting the literature review and collecting data. M.D. composed the research methodology, conducted the analysis of data and wrote the results section.

\section{References}

Aguilar, F.X., Cai, Z., Mohebalian, P. \& Thompson, W., 2015, 'Exploring the drivers' side of the blend wall: US consumer preferences for ethanol blend fuels', Energy Economics 49, 217-226. https://doi.org/10.1016/j.eneco.2015.01.019

Algier, B., 2014, 'The influence of biofuels, economic and financial factors on daily returns of commodity futures prices', Energy Policy 69, 227-247. https://doi. org/10.1016/j.enpol.2014.02.020

Babbie, E.R., 2013, The basics of social research, Cengage Learning, Boston, MA.

Bryman, A. \& Bell, E., 2015, Business research methods, Oxford University Press, New York.

Cacciatore, M.A., Scheufele, D.A. \& Shaw, B.R., 2012, 'Labeling renewable energies: How the language surrounding biofuels can influence its public acceptance', Energy Policy 51, 673-682. https://doi.org/10.1016/j.enpol.2012.09.005

Campbell, A. \& Doswald, N., 2009, The impacts of biofuel production on biodiversity: A review of the current literature, UNEP-WCMC, Cambridge.

Chakauya, E., Beyene, G. \& Chikwamba, R.K., 2009, 'Food production needs fuels too: Perspectives on the impact of biofuels in Southern Africa', South African Journal of Sciences 105, 174-181.

Chawafambira, K., 2014, No ethanol back-up, viewed 20 March 2016, from https:// www.dailynews.co.zw/articles/2014/01/21/no-ethanol-back-up-mavhaire
Creswell, J.W., 2009, Research design, qualitative, quantitative and mixed methods approaches, 3rd edn., Sage Publications, Thousand Oaks, CA.

Florin, M.J., Van De Ven, G.W.J. \& Van Ittersum, M.K., 2014, 'What drives sustainable biofuels? A review of indicator assessments of biofuel production systems involving smallholder farmers', Environmental Science \& Policy 37, 142-157.

Fouché, C.B. \& De Vos, A.S., 2011, 'Formal formulations', in A.S. De Vos, H. Strydom, C.B. Fouché \& C.S.L. Delport (eds.), Research at grass roots: For the social sciences and human service professions, pp. 89-100, Van Schaik Publishers, Pretoria.

Gan, C., Wee, H., Ozanne, L. \& Kao, T., 2008, 'Consumers' purchasing behaviour towards green products in New Zealand', Innovative Marketing 4(1), 93-102.

Ginsberg, J. \& Bloom, P., 2004, 'Choosing the right green marketing strategy', MIT Sloan Management Review 46(1), 79-84.

Graneheim, U.H. \& Lundman, B., 2004, 'Qualitative content analysis in nursing research: Concepts, procedures and measures to achieve trustworthiness', Nurse Education Today 24, 105-112. https://doi.org/10.1016/j.nedt.2003.10.001

Guba, E.G. \& Lincoln, Y.S., 1994, 'Competing paradigms in qualitative research', in N.K. Denzin \& Y.S. Lincoln (eds.), The handbook of qualitative research, pp. 105-117, Sage, Thousand Oaks, CA

Hartmann, P. \& Apaolaza-Ibanez, V., 2012, 'Consumer attitude and purchase intention toward green energy brands: The roles of psychological benefits and environmental concern', Journal of Business Research 65(9), 1254-1263. https:// doi.org/10.1016/j.jbusres.2011.11.001

Henley, G., 2014, Markets for biofuel producers in Southern Africa: Do recent changes to Legislation in the Region and EU Bring New Opportunities?, EPS-Peaks report, Overseas Development Institute, London.

Hertel, T.W. \& Tyner, W.E., 2013, 'Market-mediated environmental impacts of biofuels', Global Food Security 2(2), 131-137. https://doi.org/10.1016/j.gfs.2013.05.003

Huang, J., Yang, J., Msangi, S., Rozelle, S. \& Weersink, A., 2012, 'Global biofuel production and poverty in China', Applied Energy 98, 246-255. https://doi. org/10.1016/j.apenergy.2012.03.031

Jaeger, W.K. \& Egelkraut, T.M., 2011, 'Biofuel economics in a setting of multiple objectives and unintended consequences', Renewable and Sustainable Energy Reviews 15(9), 4320-4333. https://doi.org/10.1016/j.rser.2011.07.118

Kallas, Z. \& Gil, J.M., 2014, 'Consumers' preferences towards biodiesel in the Spanish transport sector: A case study in Catalonia', in 2014 International Congress, European Association of Agricultural Economists, Ljubljana, Slovenia (No. 182801), August 26-29, 2014.

Khachatryan, H., Joireman, J. \& Casavant, K., 2013, 'Relating values and consideration of future and immediate consequences to consumer preference for biofuels: $A$ three-dimensional social dilemma analysis', Journal of Environmental Psychology 34, 97-108. https://doi.org/10.1016/j.jenvp.2013.01.001

Lawrence, J. \& Tar, U., 2013, 'The use of grounded theory technique as a practical tool for qualitative data collection and analysis', The Electronic Journal of Business Research Methods 11(1), 29-40.

Lazarus, B., 2014, Communion: Mavhaire must answer questions over Rautenbach Saturday, viewed 15 June 2014, from http://www.sundaymail.co.zw/communionmavhairemust-answer-questions-over-rautenbach/

Lee, R.A. \& Lavoie, J.M., 2013, 'From first- to third-generation biofuels: Challenges of producing a commodity from a biomass of increasing complexity', Animal Frontiers 3(2), 6-11. https://doi.org/10.2527/af.2013-0010

Ministry of Energy and Power Development, 2013, Blending saves $\$ 40$ million annually, viewed 20 June 2015, from http://www.herald.co.zw/blendingsaves$40 \mathrm{~m}$-annualyy/

Mohr, A. \& Raman, S., 2013, 'Lessons from first generation biofuels and implications for the sustainability appraisal of second generation biofuels', Energy Policy 63, 114-122. https://doi.org/10.1016/j.enpol.2013.08.033

Moyo, P., Moyo, M., Dube, D. \& Rusinga, O., 2014, 'Biofuel policy as a key driver for sustainable development in the biofuel sector: The missing ingredient in Zimbabwe's biofuel pursuit', Modern Applied Science 8(1), 36.

Murphy, R., Woods, J., Black, M. \& McManus, M., 2011, 'Global developments in the competition for land from biofuels', Food Policy 36, 52-61. https://doi. org/10.1016/j.foodpol.2010.11.014

Negash, M. \& Swinnen, J.F., 2013, 'Biofuels and food security: Micro-evidence from Ethiopia', Energy Policy 61, 963-976. https://doi.org/10.1016/j.enpol.2013.06.031

O'Brien, B.C., Harris, I.B., Beckman, T.J., Reed, D.A. \& Cook, D.A., 2014, 'Standards for reporting qualitative research: A synthesis of recommendations', Academic Medicine 89(9), 1245-1251. https://doi.org/10.1097/ACM.0000000000000388

Pacini, H., Assunçao, L., Van Dam, J. \& Toneto, R., 2013, 'The price for biofuels sustainability', Energy Policy 59, 898-903. https://doi.org/10.1016/j. enpol.2013.03.042

Pembere, K., 2013, Government raise fuel blending ratio, viewed 07 July 2015, from $\mathrm{http} / /$ :www.herald.co.zw/gvt-raise-blending-ratio/

Peters, M., Fudge, S. \& Sinclair, P., 2010, 'Mobilising community action towards a lowcarbon future: Opportunities and challenges for local government in the UK' Energy Policy 38(12), 7596-7603. https://doi.org/10.1016/j.enpol.2010.01.044

Petrolia, D.R., Bhattacharjee, S., Hudson, D. \& Herndon, C.W., 2010, 'Do Americans want ethanol? A comparative contingent-valuation study of willingness to pay for $\mathrm{E}-10$ and E-10', Energy Economics 32, 121-128. https://doi.org/10.1016/j. eneco.2009.08.004

Pickelsimer, C. \& Esterhuizen, D, 2011, Zimbabwe biofuel situation update 2010 Gain report, viewed 14 July 2016 from https://gain.fas.usda.gov/.../Biofuels\%20 situation $\% 20$ update $\% 202010$ Pretoria_Zimbabwe 
Pilgrim, S. \& Harvey, M., 2010, 'Battles over biofuels in Europe: NGOs and the politics of markets', Sociological Research Online 15(3), 1-4. https://doi.org/10.5153/ of markets
sro. 2192

Proost, S. \& Van Dender, K., 2012, 'Energy and environment challenges in the transport sector', Economics of Transportation 1(1), 77-87. https://doi.org/10.1016/j. ecotra.2012.11.001

Ricci, M., Bellaby, P. \& Flynn, R., 2010, 'Engaging the public on paths to sustainable energy: Who has to trust whom?', Energy Policy 38(6), 2633-2640. https://doi. org/10.1016/j.enpol.2009.05.038

Rogers, J., Simmons, E., Convery, I. \& Weatherall, A., 2012, 'Social impacts of community renewable energy projects: Findings from a wood fuel case study' Energy Policy 42, 239-247. https://doi.org/10.1016/j.enpol.2011.11.081

Saruchera, F., Phiri, M.A. \& Chitakunye, P., 2014, 'Consumer perceptions about E10 fuel in Zimbabwe: Managerial implications', Journal of Contemporary Management 11, 470-490.

Selfa, T., Kulcsar, L., Bain, C., Goe, R. \& Middendorf, G., 2011, 'Biofuels bonanza? Exploring community perceptions of the promises and perils of biofuels
production', Biomass and Bioenergy 35(4), 1379-1389. https://doi.org/10.1016/j. production', Biomass a
biombioe.2010.09.008

Shonhiwa, C.S., Nhamo, L.M.N. \& Chinguwa, S., 2013, 'The techno-economic impact of petrol-ethanol fuel blends on light duty vehicles: Case study - Zimbabwean petrol vehicle fleet', paper presented at the International Council for Science petrol vehicle fleet', paper presented at the International Council for Science
(ICSU) Regional Implementation Workshop on Sustainable Energy in Sub-Saharan (ICSU) Regional Implementation Works
Africa, May 7-8, 2013, Nairobi, Kenya.
Silverman, D. \& Marvasti, A., 2008, Doing qualitative research: A comprehensive guide, Sage, Thousand Oaks, CA.

Sims, R.E., Mabee, W., Saddler, J.N. \& Taylor, M., 2010, 'An overview of second generation biofuel technologies', Bioresource Technology 101(6), 1570-1580. https://doi.org/10.1016/j.biortech.2009.11.046

Smith, A.L., Klenk, N., Wood, S., Hewitt, N., Henriques, I., Yan, N. \& Bazely, D.R., 2013 'Second generation biofuels and bioinvasions: An evaluation of invasive risks and policy responses in the United States and Canada', Renewable and Sustainable Energy Reviews 27, 30-42. https://doi.org/10.1016/j.rser.2013.06.013

Strauss, A. \& Corbin, J., 1998, Basics of qualitative research: Techniques and procedures for developing grounded theory, 2nd edn., Sage, Thousand Oaks, CA.

Thondhlana, G., 2014, 'The local livelihood implications of biofuel development and land acquisitions in Zimbabwe', CIGI Africa Initiative, viewed 20 September 2015, from https://www.cigionline.org/sites/default/files/ai_dp_11_0.pdf/

Tyner, W. \& Viteri, D., 2010, 'Implications of blending limits on the US ethanol and biofuels markets', Biofuels 1(2), 251-253. https://doi.org/10.4155/bfs.09.24

Van de Velde, L., Verbeke, W., Popp, M., Buysse, J. \& Van Huylenbroeck, G., 2009 'Perceived importance of fuel characteristics and its match with consumer beliefs about biofuels in Belgium', Energy Policy 37(8), 3183-3193. https://doi. org/10.1016/j.enpol.2009.04.022

Zapta, C. \& Nieuwenhuis, P., 2009, 'Driving on liquid sunshine - The Brazilian biofuel experience: A policy driven analysis', Business Strategy and the Environment 18(8), 528-541. https://doi.org/10.1002/bse.616 